\title{
Mobile Learning Design Models for State University of Jakarta, Indonesia
}

https://doi.org/10.3991/ijim.v13i09.10987

\author{
Ika Lestari ( $\left.\varpi^{\prime}\right)$, Arifin Maksum, Cecep Kustandi \\ Universitas Negeri Jakarta, Jakarta, Indonesia \\ ikalestari@unj.ac.id
}

\begin{abstract}
In facing the industrial era of 4.0, the instructional paradigm requires the involvement of technology in it. The use of technology in instructional is sometimes regarded as a medium or tool for delivering information through technology from lecturers to students without considering the learning process of students with technology that makes learning more meaningful outcomes. Meanwhile, an instructional medium such as mobile learning applications through Android is a type of mobile learning that can change the way students to communicate and interact. The use of mobile learning applications through Android is adjusted to the characteristics of students and learning needs in the industrial era 4.0. The results showed that the mobile learning application influenced academic student achievement so that the conceptual models of mobile learning was obtained in the industrial era of 4.0 for learning in college. This study concludes that mobile learning applications encourage students in fun learning activities and place students as the main subject in learning, so learning becomes meaningful.
\end{abstract}

Keywords - Mobile learning, smartphones, instructional, technology

\section{$1 \quad$ Introduction}

Since the early 2000s, mobile devices such as smartphones and tablets, is most likely to represent the rapid development of today's technology to be adopted by the world as a more sophisticated, faster, and cheaper [1] so that in the 21st century, it is not surprising that small children increasingly exposed by the media, technology, or the touch screen either at home or in a learning setting [2]. The growth of mobile device usage increases in primary school children and toddlers through their parents (an increase in mobile penetration technology) as well as the school that involves technology [3]. In the 21st century, higher education must be reconstructed to adapt to the rapid development of technology and information due to global competition, the increasing number of higher education needs and the demographic characteristics of students [4]. Rapid changes in information and communication technology have an impact on academics, especially lecturers, in involving the use of technology in learning activities. The use of technology is also supported by the emergence of an era 4.0 technology that combines automation with cyber technology. Indonesia is ready to 
supply it. Education 4.0 puts university students in the center of the ecosystem and is encouraged to determine the structure of the education path to the end.

In education 4.0, learning is connected to students, focusing on students, aimed at students and led by students. Students are responsible for determining the various dimensions of their educational path - what, where, when, how, and why climbing the learning ladder. Education 4.0 is the personalization of the learning process, where students have full flexibility to become architects of their learning pathways and have the freedom to have aspirations and achieve goals. The focus of 4.0 education is on "experiential learning" - learning from peers, social interactions, and real-world problems [5],

Indonesia is a developing country that has 359.5 million mobile customers in 2019 out of a total population of 268.2 million. Of the 355.5 million mobile customers; as many as $60 \%$ have smartphones, and $91 \%$ have cellular phones with many types [6]. Therefore, Indonesia also has a great opportunity to involve mobile learning for learning, especially with the era of the Industrial Revolution 4.0. Therefore, mobile learning has a great opportunity to be used in learning in college.

M-learning have become important factors in the learning process is not applicable for the students of the 21st century requires the use of mobile devices in learning because mobile learning can improve student learning [3], thus contributing positively to the involvement of students and its positive influence in academic [7]. Research that discusses mobile learning has been carried out, especially those relating to academic achievement or learning performance of students, but several research results are found to be different. There is research that states that mobile learning affects academic achievement, but there are also who find mobile learning that does not significantly influence academic achievement. Studies that found that mobile learning, when used appropriately, can affect academic achievement and disposition towards learning [5-7]. Other studies found that mobile learning does not have a significant effect on academic achievement [8] - [9]. But it influences learning attitudes such as motivation. This is because some students feel that mobile learning makes interaction and communication less frequent with instructors and peers, so research should further investigate ways to utilize affordability of cellular technology to achieve innovative and effective interactive mechanisms in cellular learning and search for factors that influence student academic performance and learning attitudes in the context of mobile learning [11].

M-learning can utilize the features of Moodle as the learning media platform. This research resulted in the m-learning application entitled Mobile LearningKu. Mobile LearningKu application can be accessed by downloading and installing from the Play Store to smartphones each university student through an administrator account. In general, students of Greek University chooses not to use his smartphone to access Moodle due to the limitations on the usefulness and reliability of mobile devices. Owned mobile devices more to access the learning materials in Moodle [13].

Preliminary studies were conducted in 2017 to 67 university students in Elementary School Teacher Education Program, State University of Jakarta, Indonesia, explained that the university students more use of smartphones to access Instagram and interact with other social media. Smartphone to open entertainment information car- 
ried by $56.25 \%$ university students, and they are not used to engaging online learning both inside and outside the classroom [14].

Also this is supported by the results of research conducted on students in the Elementary School Teacher Education Program, State University of Jakarta, Indonesia showing that many learning cultures that occur in universities are still relatively low; there are still many who read books solely to do assignments given by lecturers; do not have the initiative to directly learn on their own if the lecturer is absent; serious learning is done when approaching the test day; rarely read lecture material that has been studied so that when the lecture takes place, the questions asked are very superficial; assignments are often carried out in the near future on the day of collecting assignments and modeling their friends, tracing the results of references on the internet or books directly without first processing the reading results [15].

Based on the evidence reported in the literature about the positive impact of mobile learning to academic achievement and attitudes of students, this paper reviewing the learning model that accompanies the use of m-learning to improve student learning outcomes university. This study will develop m-learning applications and test the effects of the use of applications on a student's academic success of the university for prospective elementary school teachers. The main question that drives this research is, "What is the use of m-learning applications as LMS have a positive impact on student academic performance?" In this way, this research attempts to answer:

- Is there a meaningful difference between the pre-test and post-test mean scores of the mobile learning applications on university student learning outcomes?

- How to integrate a pedagogic value in mobile learning models for a university student?

- How to design mobile learning by the model for university students in State University of Jakarta, Indonesia?

\subsection{Pedagogical framework of m-learning}

M-learning supports traditional learning (face to face) for the university students in the context of informal learning, raises the communication is effective, and improve the motivation of university students so that pedagogy values of m-learning should be known well to the use of m-learning efficient. In this context, it can be said that the four basic elements that surround the frame of m-learning pedagogy are technology, pedagogy, content, and social interaction. The more successful the four basic elements is realized, m-learning will run more effectively. To that end, lecturers and m-learning software developers need to know the four basic elements [16].

Four basic elements of m-learning pedagogy that need to be considered include the integration of technology, pedagogy, assessment techniques, and teacher training that gives rise to the pedagogy appears in m-learning is constructivism, blended learning, collaborative learning, and active learning [17], The same values was found in this study. Figure 1 illustrates the pedagogical aspects contained in this research such as technology, learning activities conducted by lecturers and students, the interaction between students, lecturers, and students, and the concept of learning. This study led 
to the pedagogical value obtained from m-learning in State University of Jakarta, Indonesia.

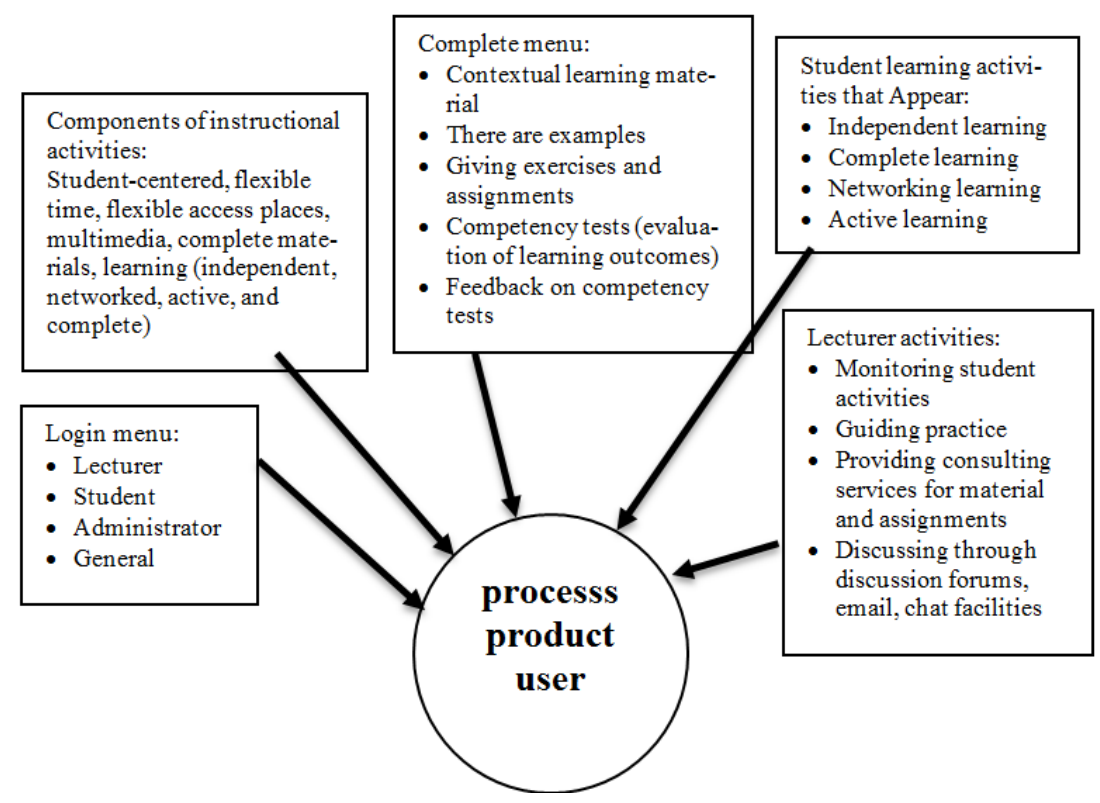

Fig. 1. Design pedagogical models of mobile learning for a university student in State University of Jakarta, Indonesia

In this study, we offer m-learning models appropriate for the student at State University of Jakarta in Indonesia. This model is expected to provide a theoretical basis to successfully apply for the skills learned in education 4.0, especially in Indonesia. There are some drawbacks of m-learning models and the framework that is based on empirical research conducted in developing countries. Developing countries have challenges associated with a unique culture, infrastructure, and learning environment.

To design m-learning models are suitable for use by students at State University of Jakarta, Indonesia, which needs to be seen first is literacy technology owned by lecturers and students, especially for professors. The findings of the study found that lecturers rarely use m-learning in learning. The instructional method usually used with the presentation of the paper in front of the class is the most widely performed by lecturers because of the limitations of technology owned by lecturers. Literacy technology owned by lecturers and students is a mandatory requirement that must meet for successful m-learning [41]. To that end, for the implementation of successful mlearning training needs to be done about m-learning is done by the faculty.

M-learning is not merely a tool or media that holds all messages learning materials for use by lecturers and students of the university. Without a pedagogical value which can not provide academic influence on university students. Technology alone can not make students want to learn; the technology makes the classification of students based on their ability to access certain technology more harm than good [18]. At present, 
what is needed by students on the skills of information analysis and find learning strategies to solve problems. Learning theory is used to assist in developing a set of instructional design principles that can be applied m-learning.

Figure 1 illustrates the existing pedagogical framework in this study. The pedagogical models of mobile learning things consist of three items, namely processes, products, users that are integrated with learning conditions, instructional methods, and learning outcomes. The learning conditions that are considered are the characteristics of learning in the form of learning objectives/obstacles and the characteristics of students. Instructional methods include how to organize learning materials, strategies for delivering, and managing activities. Learning outcomes include effectiveness, efficiency, and attractiveness of learning for students. Mobile learning brings students more opportunities to practice in doing assignments and discussions so that fostering collaborative work between students and lecturers is very likely to occur in mobile learning.

The design of the conceptual model of mobile learning in Figure 1 has provided complete menus that have to be started from the material to the evaluation. Learning evaluation is intended to understand the processes and effects of learning so that the design of learning content should be presented briefly, clearly, and easily accessible. The existing learning material should not make students linger in reading on smartphones because the resistance to reading something for someone through the screen of a smartphone is very different than through the print media. Students are given a limited amount of time in completing one learning unit in Mobile LearningKu application. Giving time for students to study a unit of learning material is limited because it is motivated by the research results of who find smartphones habits can interfere with learning activities in ways that are misused by students where they are busy focusing on social networking sites or playing the game [19]. Therefore, smartphone habits can reduce listening skills in learning activities. Attention can drop dramatically in class when students have their smartphones. Might their focus shifts from college to whatever they do on this gadget. Students believe that smartphones can be a nuisance because of the presence of social networking sites. They believe that social networking sites and WhatsApp can be a source of interference and delays.

Exercising is also available in the Mobile LearningKu application for test materials for students mastered measuring the level of competency before taking the competency tests. Interaction functions in mobile learning applications must be relevant, educational, fun, simple and safe so that they offer to learn strategies that help students adapt to complex environments, make mobile learning happened and provided a flexible and comfortable way of everyday learning [20]. Satisfaction factors that affect students in learning with mobile learning are responsive or direct feedback in the learning process and learning materials that are appropriate to the context of cellular learning.

M-learning is emphasized rather than the involvement of m-learning as a learning medium but the learning method that accompanies the involvement of m-learning. Students are more motivated to learn or stay to learn when using mobile devices in an informal environment compared to desktop computers in a formal environment [21] so that the current study will develop a model of learning that involve m-learning in 
formal learning contexts. Engagement mode of use Learning Management System (LMS) used in this study is that it combines in-person learning to use the LMS features such as communication, assessment, collaboration, and learning materials [13]. This mode is selected with consideration if a university student in Elementary School Teacher Education Program, State University of Jakarta, Indonesia, was unfamiliar with m-learning. The benefits of a mobile device that can be felt for the students are at home or willing to follow the learning procedure in m-learning [21].

\subsection{Definition of mobile learning}

In supporting education 4.0, lecturers can use mobile learning in learning activities. Mobile learning is not only about instructional material to students but more about encouraging students in fun learning activities, making students the main agents in the learning process. Since the term mobile learning was introduced in 2005 [22]. Many researchers initially defined it as a tool and technology or techno-centric [22],[4]. Changing to the "learning across multiple contexts, through social and content interactions, using personal electronic devices" [23]. This understanding brings understanding to the four core concepts of mobile learning items, namely pedagogy, technology, context, and social interaction [24]. The involvement of mobile learning in the learning process is also possible in Indonesia.

Most research about m-learning is derived from Taiwan and followed by the USA [25],[26]. Most studies about m-learning research focus on effectiveness [25], took samples from a higher education institution [26], resulted in positive outcomes [26], supported learning in the Language and Art [27], smartphone used as mobile devices [27]. Based on this, this research review on the use of m-learning in developing countries which would have a design model of the m-learning system that is different than the developed countries from the aspect of culture as well as its characteristics.

\section{$2 \quad$ Method}

This research was conducted for three years from 2017 to 2019 on the campus of the State University of Jakarta, Indonesia.

\subsection{Research design}

This research is included in the experimental research design that uses preexperiment one group pretest-posttest. This design involves one group was given a pre-test $(\mathrm{O})$, treatment $(\mathrm{X})$, and post-test. The success of the treatment is determined by comparing the pre-test and post-test. In the pre-experimental study, one group pretest post-test, the first step is to determine the samples to be used as samples and breaks it down into one class research. The next stage is to provide pre-test to measure learning outcomes before being given treatment using a mobile learning application. The next stage, the samples are given the treatment the use of mobile learning applications. Then, at the last stage, samples are given a post-test to measure outcomes after 
treatment given the use of mobile learning applications. Table 1 describes the study design:

Table 1. The research design of mobile learning models

\begin{tabular}{|c|c|c|}
\hline Pretest & Treatment & Posttest \\
\hline $\mathrm{O} 1$ & $\mathrm{X}$ & $\mathrm{O} 2$ \\
\hline
\end{tabular}

Description:

$\mathrm{O} 1=$ pretest given before treatment

$\mathrm{O} 2=$ posttest given after treatment

$\mathrm{X}=$ Treatment in the form of using Mobile LearningKu application

\subsection{Population and sample research}

The population taken was students in the Student Development Course in the year 2018/2019 as many as 77 university students. The same retrieval technique is Carried out by taking the entire population, considering that there are only 77 students.

\subsection{Research instruments}

The instrument used is a cognitive achievement test subjects for Development of Students who use Mobile LearningKu app. The research instrument, before being used to collect data, do a trial first in the field. The validity of the instruments used in compiling this research instrument is content validity and construct validity. The validity of the content will show the extent to which the research instrument reflects the desired contents. In this study, the validity of the content is done by consulting these instruments to multiple parties which are considered experts on the subject while the construct validity by calculating the validity of test with correlation techniques from Karl Pearson Product Moment as shown in Figure 2.

$$
r_{x y}=\frac{N \sum X Y-\left(\sum X\right)\left(\sum Y\right)}{\sqrt{\left(N \sum X^{2}-\left(\sum X\right)^{2}\right)\left\{N \sum Y^{2}-\left(\sum Y\right)^{2}\right\}}}
$$

Fig. 2. Product Moment correlation from Karl Pearson

Information :

$r$ by: The correlation coefficient between variables $\mathrm{X}$ and $\mathrm{Y}$

$\mathrm{N}$ : Number of respondents

$\Sigma X Y$ : Number of multiplying the score of $\mathrm{X}$ and $\mathrm{Y}$

$\Sigma X 2$ : Number of $X$ squared

$\Sigma Y 2$ : Number of $Y$ squared

$\Sigma \mathrm{X}$ : Total score $\mathrm{X}$

$\Sigma \mathrm{Y}$ : Total score $\mathrm{Y}$ 
Decision-making criteria for determining whether or not a matter is valid by comparing the count $\mathrm{r}$ ( $\mathrm{r} x y$ ) with $\mathrm{r}$ table at a significance level of $5 \%$. If $\mathrm{r} x y$ count is greater than or equal to $r$ table then tested instrument is declared invalid. If $r$ xy is smaller than $r$ table, then tested instrument is not valid. Value using the Pearson correlation coefficient $r$ table $=0227$ at a significance level of $\leq 0: 05$. Validity test calculations using the computer program SPSS version 22.0. Validity test results the use of mobile learning applications that have been performed by testing of 25 items using SPSS 22.0 statement obtained results the validity of test results count learns when to use mobile learning application as follows.

Reliability test in this study using Cronbach Alpha formula is the formula used to calculate the scale multilevel data. The Cronbach Alpha formula, as shown in Figure 3 .

$$
\mathbf{r}_{11}=\left[\frac{k}{(k-1)}\right]\left[1-\frac{\sum \sigma_{b}{ }^{2}}{\sigma_{t}{ }^{2}}\right]
$$

Fig. 3. Cronbach alpha formula

Information :

r11 : Reliability instruments.

$\mathrm{k} \quad$ : Many of the items.

$\Sigma \sigma 2 b$ : The number of variants of the item.

$\sigma 2 \mathrm{t}:$ Number of the total variances

\subsection{Data analysis}

Normality test is done on the pretest and posttest scores using the formula Kolmogorov Smirnov conducted with the rules Asymp. Sig or the p-value at a significance level of $5 \%$ alpha. If $\mathrm{p}>0.05$, then the data is normally distributed. Normality calculations using SPSS version 22.0. After the normality test, then the test of homogeneity. To test the homogeneity of statistical variance test (test of variance) on the distribution of the groups concerned. Homogeneity test carried out on a score of pretest and posttest with the rules if the significance value is bigger than the significance level of $0.05(5 \%)$. Homogeneity test used by paired sample t-test is to determine whether there are differences in the average of two samples (two groups) are paired or associated. Calculation of homogeneity done with SPSS version 22.0.

The data analysis technique used to test the hypothesis in this study is the t-test. The t-test is intended to test the average value of the pretest, and posttest values have significant differences. Data analysis technique performed using SPSS 22.0. Interpretation of t-test results to see the value of Sig. (2-tailed), and then compared with a significance level of 0.05 . Terms of data are significant if the p-value is smaller than the significance level of $5 \%$. 


\section{Results}

\subsection{System interface}

Below is some description related to the interface of the mobile application.

Login page: The mobile learning application created is given the name Mobile LearningKu and can be installed by students in the Play Store by simply typing the name "Mobile LearningKu." After downloading and installing, the next application can be used in the lecturer and student's smartphone. This application requires an administrator to create and manage student and lecturer accounts. This account is useful for accessing the application so that it must be remembered by every user. The display of the Mobile LearningKu application in a smartphone can be seen in Figure 4.

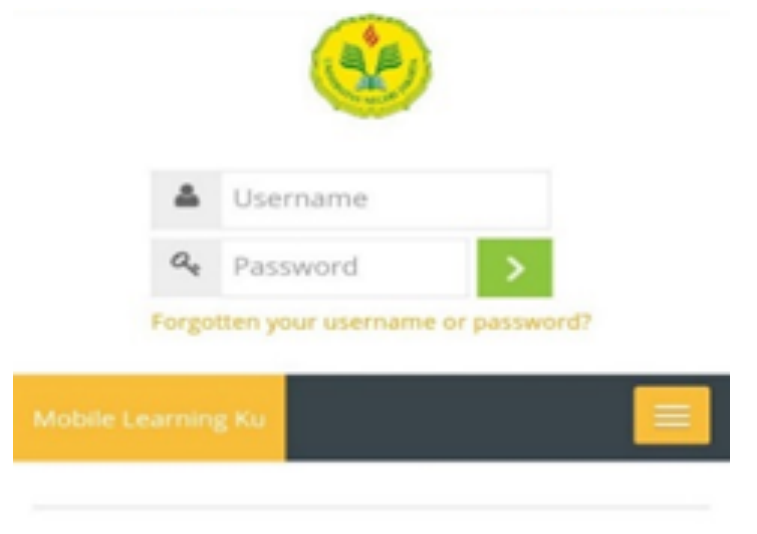

\section{Available courses}

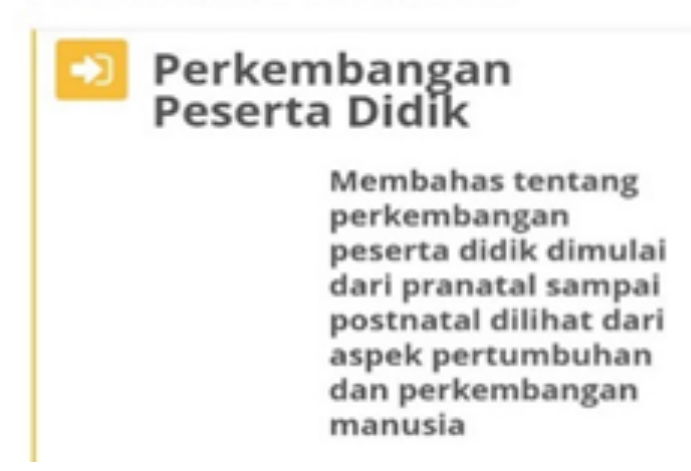

Fig. 4. Login page of Mobile LearningKu applications on a smartphone when it is opened

Content menus: After entering the user account into the application, students can then see a list of menus in the application and choose the menus that are want to learn. The material in the subject Development of Students deliberately made procedurally 
means that university students cannot start learning as they wish. Instructional materials must be studied in stages by students. The important thing to be noticed by lecturers when determining to learn in mobile learning is that they are required to fill instructional materials and tests that must be read and done by students. Figure 5 describes the list of materials menus and tests from the Student Development Course.

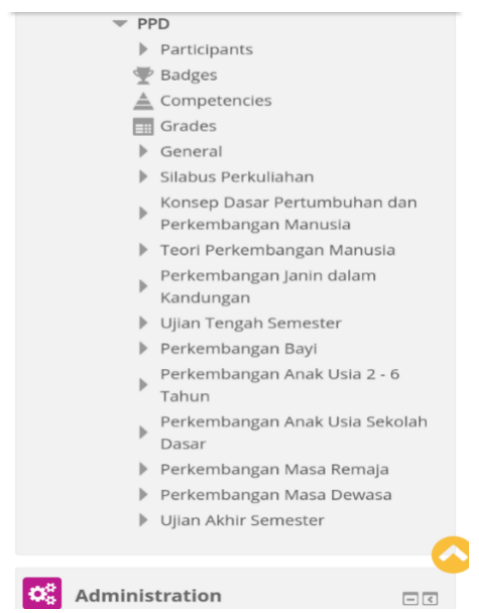

Fig. 5. Display the menu list in Mobile LearningKu application

Each menu in the list of learning materials consists of material, videos, quizzes, and impressions and messages (where students discuss or respond to the material and tests, this can be an input for lecturers to improve the material displayed). Figure 6 shows a list of sub-menus in the mobile learning application.

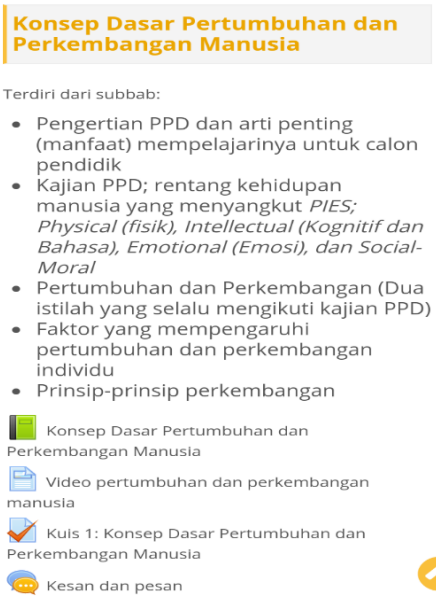

Fig. 6. Display a list of sub-menus in Mobile LearningKu application 
Practice / evaluation page: In this application, there are pages for measuring learning evaluation capability from university students. With this menu, the lecturer can upload test, or the make a direct test with more evaluation types such as multiple choice and essay. Students can see their scores in evaluations page. Figure 7 describes the display from the evaluation page.

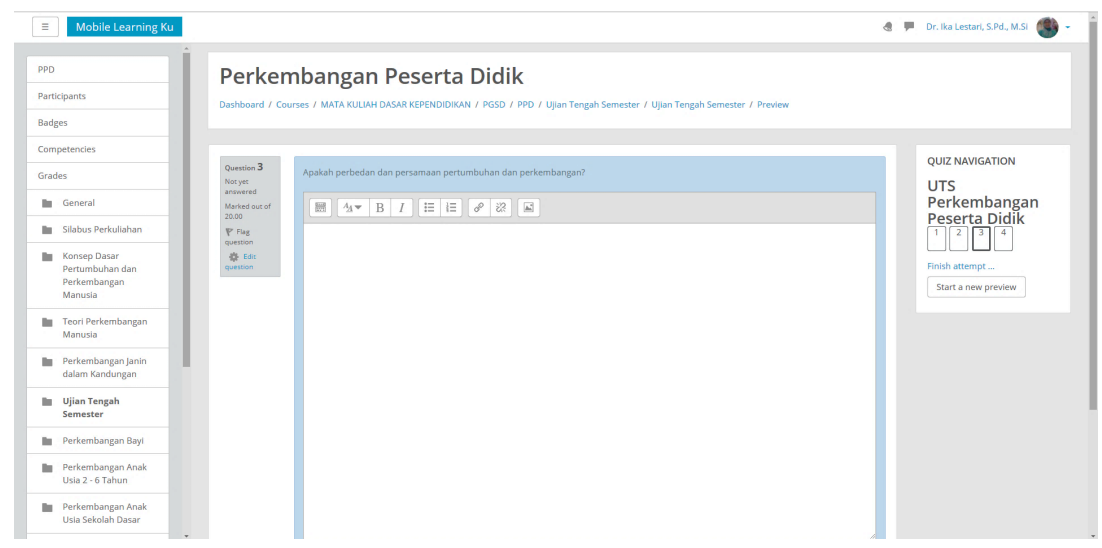

Fig. 7. Display from evaluation page

Achievement page: After each student completed the evaluation of learning, this page will display the results of learning. Through this page, the lecturer can know to what extent students are learning progress. The example for this page can be shown in figure 8 .

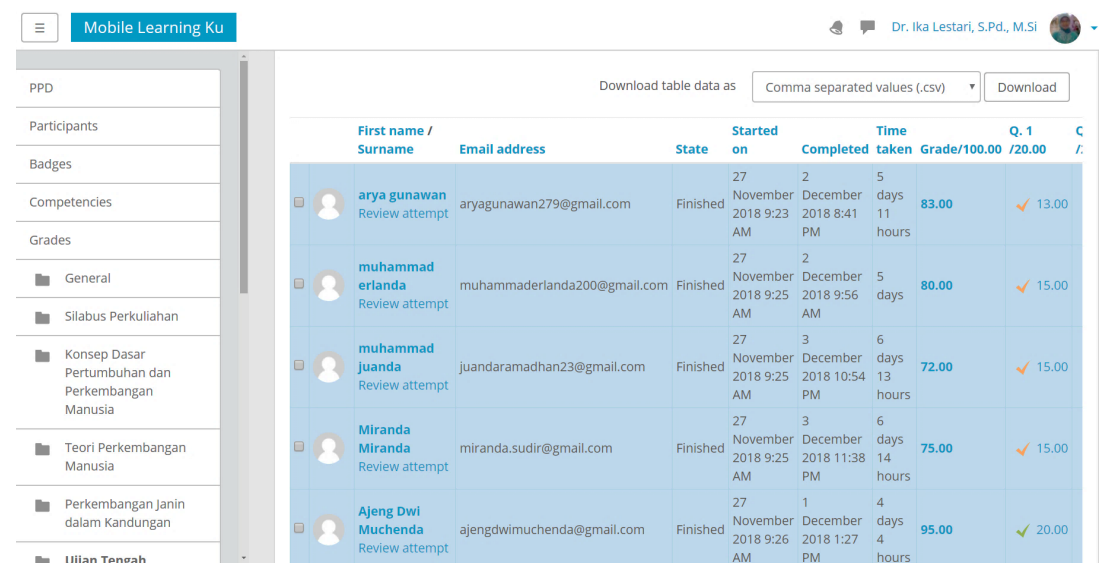

Fig. 8. Achievement page 


\subsection{The effect of the Mobile LearningKu application on learning outcomes}

Based on learning outcomes of test data analysis requirements were tested to determine the level of normality and homogeneity of the research data that pretest and posttest values obtained university student when yet and after use Mobile LearningKu application. The normality Kolmogorov-Smirnov test uses the formula of the which is carried out with the Asymp rule. Sig or p-value at the alpha significance level of 5\%. If $p>0.05$, the data is normally distributed. This normality calculation uses SPSS version 22.0 computer assistance. The results of the normality test calculated using SPSS version 22.0 can be seen in table 2 .

Table 2. Results of the normality test (NPar Tests)

\begin{tabular}{|c|c|c|}
\hline \multicolumn{3}{|c|}{ One-Sample Kolmogorov-Smirnov Test } \\
\hline & & Residual unstandardized \\
\hline \multicolumn{2}{|l|}{$\mathrm{N}$} & 77 \\
\hline \multirow[t]{2}{*}{ Normal Parameters, $\mathrm{b}$} & mean & .0000000 \\
\hline & Std. deviation & 10.96065095 \\
\hline \multirow[t]{3}{*}{ Most Extreme Differences } & Absolute & .104 \\
\hline & positive & .054 \\
\hline & negative & -.104 \\
\hline \multicolumn{2}{|l|}{ Test Statistic } & .104 \\
\hline \multicolumn{2}{|l|}{ Asymp. Sig. (2-tailed) } & $.040 \mathrm{c}$ \\
\hline \multicolumn{3}{|l|}{ a. Test distribution is Normal. } \\
\hline \multicolumn{3}{|c|}{ b. Calculated from data. } \\
\hline \multicolumn{3}{|c|}{ c. Significance Lilliefors Correction. } \\
\hline
\end{tabular}

The test results of proving that if $p>0.05$, then the data is normally distributed because the results of $p=0.040>0.05$ then the data from the pretest and posttest are said to have a normal distribution. Next will be a homogeneity test. To homogeneity, a test of variance is carried out on the distribution of the groups concerned. The homogeneity test was carried out on the pretest and posttest scores with rules if the calculated significance value was greater than the significance level of 0.05 (5\%). Calculation of homogeneity carried out with the help of the computer program SPSS version 22.0 can be seen in Table 3 .

Table 3. Test of homogeneity of variances (pretest)

\begin{tabular}{|c|c|c|c|}
\hline Levene Statistic & DF1 & DF2 & Sig. \\
\hline 1,020 & 14 & 54 & .449 \\
\hline
\end{tabular}

The hypothesis proposed for this similarity variance test is:

$\mathbf{H}_{\mathbf{0}}$ : The variance in each group is homogeneous

$\mathbf{H}_{\mathbf{1}}$ : The variance in each group is different (not homogeneous)

Based on the SPSS output above it is known that the significance value is 0.449 the which indicates greater than 0.05 so that it can be concluded that the tested the data shows the same variance (homogeneous) the which means is accepted. Because the data from the calculation results on the normality and homogeneity tests show normal and homogeneous, then the ones used to test the effectiveness of the product are pa- 
rametric statistics through t-test (t-test) using the Paired Samples Test formula. Table 4 describes the t-test output.

Table 4. Paired samples test

\begin{tabular}{|c|c|c|c|c|c|c|c|c|c|}
\hline & \multicolumn{5}{|c|}{ Paired Differences } & \multirow[t]{3}{*}{$\mathbf{t}$} & \multirow[t]{3}{*}{ df } & \multirow[t]{2}{*}{$\begin{array}{l}\text { Sig. (2- } \\
\text { tailed) }\end{array}$} \\
\hline & & \multirow[t]{2}{*}{ mean } & \multirow[t]{2}{*}{$\begin{array}{c}\text { Std. } \\
\text { deviation }\end{array}$} & \multirow[t]{2}{*}{$\begin{array}{c}\text { Std. error } \\
\text { Mean }\end{array}$} & \multicolumn{2}{|c|}{$\begin{array}{l}\text { 95\% Confidence } \\
\text { Interval of the } \\
\text { Difference }\end{array}$} & & & \\
\hline & & & & & Lower & Upper & & & \\
\hline pair 1 & $\begin{array}{l}\text { Pretest - } \\
\text { posttest }\end{array}$ & -8909 & 12894 & 1,469 & -11836 & -5982 & -6063 & 76 & .000 \\
\hline
\end{tabular}

Based on the output, it is known that the Sig. (2-tailed) of $0.000>0.05$, because of the value of Sig. (2-tailed) Equal to 0,000 smaller 0.05, then it can be concluded if the use of mobile learning can improve or have a positive effect on learning outcomes in the course of Student Development. The results of this study are the same with several studies agree that if mobile learning has an effective influence on academic achievement or can increase the learning outcomes [13-14]. Also, developers strive to improve learning efficiency by using mobile learning applications [30].

\section{$4 \quad$ Findings and Discussion}

The research questions need to answer is about the influence of mobile learning models on learning outcomes, a pedagogic value in mobile learning models for university student, and design a mobile learning model by for university students in State University of Jakarta, Indonesia.

\subsection{The cause of the positive effects of mobile learning on learning outcomes}

Mobile learning has a positive influence on academic achievement because their students can access lessons and send assignments through mobile devices whenever and wherever [29], the teacher can also upload learning materials, determine discussions and accept assignments electronically, but contrary to the other researchers found no influence between mobile learning on academic achievement, mobile learning influences the learning of learner motivation because it creates enthusiasm in learning because of the interactive classroom environment [12]. The other researchers also found that there was no influence between mobile learning and academic achievement; mobile learning had a more positive effect on communication and interaction skills and higher-order thinking skills [31]. That study highlights the importance of mobile devices in the classroom, but which the influences not on academic achievement but rather on learning motivation.

Many studies show that teachers in Indonesia have a positive perception of mobile devices [18-19], as well as students who have positive perceptions of learning [34]. 
Studies that prioritize the elements of technology as a delivery tool in mobile learning can result in no effect of mobile learning on student academic achievement.

Theoretical, pedagogical, methodological issues related to the integration of technological devices into the educational context should be more valued [35]. Pedagogical values found in mobile learning are the introduction of students in understanding the scope and format of mobile learning activities. This is important because not all lecturers use mobile learning in the classroom. Students need to feel "hooked" for the first session of the lecture. Attractive and interactive impressions need to be raised in the application of mobile learning and continuous encouragement from lecturers so that students are involved in learning activities need to be done. The reward system needs to be carried out by the lecturer at the beginning of the introduction of the mobile learning application but then becomes the task of the lecturer to motivate students to want to learn by using mobile learning. Limit the number of discussion forums that are not related to material topics and provide a question and answer menu to discuss topics of interest to students. Student opinions or suggestions in improving the learning plan need to be done so that students feel involved in making the plan so that they can focus on the material being studied. Required activities to facilitate student interaction with classmates through the mobile learning application. Expanding student access to message forums (to read and post) with mobile devices makes the definition of mobile learning to move from technological mobility to student mobility [36].

Mobile learning is used more to encourage collaboration, to facilitate communication, to support performance, and to store evidence of activities, and to know the characteristics of its users. When the characteristics of the user are known, it is easy to design the best way to use mobile learning to learn students and know how people use their smartphones. It is difficult for students to do assignments and read material on a smartphone for 60 minutes. Things that Might Be done by students are reading the material before test preparation or communicating with fellow students [37]. In 2012, Google researched user behavior in using computers, tablets, smartphones, and televisions. The results of the research prove if the user chooses the device used for the given work depending on location, destination, time availability, and attitude. Lecturers should give assignments when considering the time spent from 2 to 20 minutes, and assignments that are appropriate for different locations such as at home, work, study or leave the field. Component attitudes can be seen from the students' interest when choosing tasks that match their interests at that time [37].

The results of research from Google also found that users performed sequential screening and simultaneous screening. Sequential screening is the act of using more than one media with the same task, for example, students use computers to do research assignments, but taking evidence in the field uses their smartphone while simultaneous screening is the use of multiple media at one time but with different objectives such as a student watching the news on television while taking photos, videos, and notes for assignments on a tablet or smartphone. The concept of mobile learning more looks at the use of multiple media [37], Google concluded the use of multiple media for learning items, namely: 
- Understanding how people consume digital media and adjusting learning strategies for each media

- Learning objectives must be adjusted to take into account the differences inherent in each device

- Students must save learning progress in devices

- Students must be easily find learning platforms on each device

- Once on the learning platform, it's easy for students to find quickly intervening searched

- Smartphones are the backbone of daily learning media usage, so learning design starts on smartphones and continues on tablets or desktop computers [37].

Users who can take advantage of the Mobile LearningKu application consist of lecturers, students, administrators, and the public even though for general users only can read menus that are in the application without have access to enter the application as students. The Mobile LearningKu application design is specifically for users such as lecturers and students. Interactions that appear in mobile learning activities such as the interaction between lecturers and students, students with the media, student participation in discussion forums, and collaboration between students. In learning using a Mobile LearningKu application, the lecturer has the authority to control the interactions that occur within the application. With limited time adapted to the complexity of competencies in each learning material,

\subsection{Pedagogical values from mobile learning}

Lecturers are required to create learning scenarios that will be poured into the learning application. Indirectly, the use of Mobile LearningKu applications leads students towards independent learning, complete learning, networking, and active learning. Figure 1 describes the design of the models of mobile learning for State University of Jakarta in Indonesia. In figure 1, it can be seen that the learning is not focused on "what is learned," but on "how to make students experience the learning process," i.e., ways to achieve goals related to ways of organizing the material, the way the lesson and how to manage to learn.

There are several new pedagogical values that meet the needs of the 21st-century student, had supported the nature of learning m-learning and the nature of today's society.

Social constructivism: Social constructivism is a pedagogical value in m-learning [38] - [40]. Social constructivism refers to learning as a result of active participation in the "group" in which new understandings constructed jointly by the student and his group, as well as knowledge as a result of the agreement. Social constructivism emphasizes the importance of interaction with others such as peers, teachers, and parents to build knowledge that is required mediation in building knowledge. The learning process is the best place amid social interaction [40] In the learning constructivist, a change in the role that happen by lecturers. Learning no longer take place in a "topdown" or traditional, but takes place from bottom to top in which teachers facilitate and not directing, what and how students learn the concepts of both inside and outside 
the classroom. In the setting of learning by using mobile phones, the lecturer should have a major role in establishing the learning environment for students. The teacher's role is as a facilitator, trainer, and student representatives. Its responsibility is to assist and guide students along with the knowledge acquired. Role as guiding students is, to motivate students to excel beyond the current level of student skills (i.e. activate the zone of proximal development of students); the student is seen as builders of knowledge.

Heutagogy: Heutagogy an extension of andragogy very student-centered. Students share content and resources in their own way. Also, the students' self-efficacy increased when students experience positive emotional satisfaction of the learning experience [41]. Pedagogy is the management of self-managed learners; students are very autonomous and self-governing. The lecturers in heutagogy provide resources and guidance to student learning, learning to negotiate, determine what will be learned and how it learned [42].

Rhizomatic learning: In the rhizomatic instructional model, the curriculum is not made by experts, but rather constructed and negotiated in real time by those involved in the learning process. Groups involved in it act as curriculum, spontaneously forming, constructing, and reconstructing itself and the subject of their lesson with the same way [41],[43].

Connectivism: Connectivism explains that knowledge is distributed across a network connection, and therefore, the learning consists of the ability to build up a network and across the [41]. Learning is considered as the process of connecting resources and students so personal learning environment and open network learning environment.

Navigationism: Navigationisme is the paradigm of learning in which students discover, identify, manipulate, and evaluate information and knowledge. Successful learning occurs when students solve real-life problems or contextually through active involvement in problem-solving activities and wide area networks, communication, and collaboration. The purpose of this activity is not to acquire or create knowledge but to solve the problem. Knowledge, of course, created in the process, but the creation of knowledge is not the sole focus of activities [41]

\section{Conclusion}

The results of the study concluded that the use of the Mobile Learningku application had a positive influence on student academic achievement due to the use of learning the theoretical framework of rules that needed to include elements of learning conditions, learning methods, and learning outcomes. Active interactions between lecturers and students, students with the media, and between students need to be created within the application through this interaction process can be implemented learning methods properly. Mobile learning is only a learning aid that will not change or improve academic performance if it is only seen as a means of storing material and giving assignments without providing learning scenarios that must be in it. Pedagogical values should be in a learning medium so that the lecturer must design learning 
that fits the criteria with mobile learning. Consideration of learning objectives, competencies to be achieved, the readability of the material, practice questions, competency tests, giving additional assignments, and guiding students through chat facilities menus and group menus.

The next research that can be done by the next researcher is monitoring mobile learning in teacher education. The success of instructional media is carried out if the lecturer can design instructional media so that the ability to create and manage to learn needs to be seen in teacher education. The results of the research that will be obtained in teacher education can be a direct improvement for teacher quality material so that students will feel qualified teachers in the classroom. The findings of this research have limitations. This study just measured learning outcomes for one public in State University of Jakarta, Indonesia, is needed so that the future research to review several higher education students (to represent the whole population of university students in Indonesia).

\section{Acknowledgement}

This research was funded by the Ministry of Research, Technology, and Higher Education through the National Strategic Grants from 2017 to 2019. Researchers are grateful for students who are willing to be involved in this research.

\section{$7 \quad$ References}

[1] Gezgin, D.M. \& Edirne, The effect of mobile learning approach on university students' academic success for database management systems course. Int. J. Distance Educ. Technol., 17(1), 15-30, 2019. https://doi.org/10.4018/ijdet.2019010102

[2] Sharkins, K.A., Newton, A.B., Essa, N. \& Ernest, J.M. Preschool children's exposure to the media, technology, and screen time: Perspectives of caregivers from three early childcare settings. Early Child. Educ. J., 44(5), 437-444, 2015. https://doi.org/10.1007/s10643-015$\underline{0732-3}$

[3] Papadakis, S. \& Kalogiannakis, M. Mobile educational applications for children: what educators and parents need to know. Int. J. Mob. Learn. Organ., 11(3), 256-277, 2017. https://doi.org/10.1504/ijmlo.2017.085338

[4] Keskin, N.O. \& Kuzu, A. Development and testing of a m-learning system for the professional development of academics through design-based action research. Int. Rev. Res. Open Distrib. Learn., 16(1), 193-220, 2015. https://doi.org/10.19173/irrodl.v16i1. $\underline{1613}$

[5] FICCI Higher Education, Leapfrogging to education 4.0 - Student at the core," November 31-35, 2017.

[6] We are Social, Digital 2019: Global internet use accelerates. We are Social and Hootsuite, 2019. [Online]. Available: https://wearesocial.com/blog-/2019/01/digital-2019-globalinternet-use-accelerates.

[7] Karsenti, T., Fievez, A., Collin, S., \& Roy, N. The iPad in education: The uses, benefits, and challenges. A survey of 6057 students and 302 teachers in Quebec, Canada. Montreal, QC: CRIFPE, 2013. 
[8] Lu, M. Effectiveness of vocabulary learning via mobile phone. J. Comput. Assist. Learn., 24(6), 515-525, 2008. https://doi.org/10.1111/j.1365-2729.2008.00289.x

[9] Huang, Y., Lin, Y., \& Cheng, S. Effectiveness of a mobile plant learning system in a science curriculum in taiwanese elementary education. Comput. Educ., 54(1), 47-58, 2010. https://doi.org/10.1016/j.compedu.2009.07.006

[10] Chu, H., Hwang, G., \& Tsai, C. A knowledge engineering approach to developing mindtools for context- aware ubiquitous learning. Computers \& Education, 54(1), 289-297, 2010. https://doi.org/10.1016/j.compedu.2009.08.023

[11] Xue, J., Zhang, X., \& Luo, H. Effects of mobile learning on academic performance and learning attitude in a college classroom. in International Conference on Advanced Education and Management, March 2018, 1-6.

[12] Miller, H.B., \& Cuevas, J. Mobile learning and its effects on academic achievement and student motivation in middle grades students. Int. J. Scholarsh. Technol. Enhanc. Learn. 1(2), 91-110, 2017.

[13] Papadakis, S.J., Kalogiannakis, M., Sifaki, E., \& Vidakis, N. Evaluating moodle use via smart mobile phones: A case study in a Greek University, Endorsed EAI Trans. Creat. Technol, 5(16), 1-9, 2018. https://doi.org/10.4108/eai.10-4-2018.156382

[14] Lestari, I. \& Yarmi, G. Conceptual models of mobile learning based moodle for learning in higher education. in Proceedings of the 1st International Conference on Education Innovation (ICEI), 399-405, 2017.

[15] Yuliati, S.R. \& Lestari, I. Higher-order thinking skills (HOTS) analysis of students in solving HOTS question in higher education. Perspektif Ilmu Pendidikan, 32(2), 181-188, 2018. https://doi.org/10.21009/pip.322.10

[16] Hwang, G., Wu, P., \& Ke, H. An interactive concept map approach to supporting mobile learning activities for natural science courses. Comput. Educ., 57(4), 2272-2280, 2011. https://doi.org/10.1016/j.compedu.2011.06.011

[17] Ozdamli, F. Pedagogical framework of m-learning. Procedia - Soc. Behav. Sci., 31, 927931, 2012

[18] Koutropoulos, A. Digital natives: Ten years after. JOLT - Journal of Online Learning and Teaching, 7(4), 2011.

[19] Razzaq, A., Samiha, Y.T., \& Anshari, M. Smartphone habits and behaviors in students supporting self-efficacy. Int. J. Emerg. Technol. Learn., 13(2), 94-109, 2018. https://doi. org/10.3991/ijet.v13i02.7685

[20] Liu, L., Zhang, L., Ye, P., \& Liu, Q. Influence factors of satisfaction with mobile learning APP: An empirical analysis of China. Int. J. Emerg. Technol. Learn., 13(3), 87-99, 2018. https://doi.org/10.3991/ijet.v13i03.8381

[21] Sung, E. \& Mayer, R.E. Online multimedia learning with mobile devices and desktop computers: An experimental test of Clark 's methods-not-media hypothesis. Computers in Human Behavior, 29(3), 639-647, 2013. https://doi.org/10.1016/j.chb.2012.10.022

[22] Jayatilleke, G., Ranawaka, G.R., Wijesekera, C., \& Kumarasinha, M.B. Development of mobile applications through design-based research. Asian Assoc. Open Univ. J., 13(2), 145-168, 2018. https://doi.org/10.1108/aaouj-02-2018-0013

[23] Berge, Z.L., Muilenburg, L.Y., \& Roberts, J.B. Accessibility in m-learning: Handbook of mobile learning. London: Routledge, 2017.

[24] Wu, P., Hwang, G., Su, L., \& Huang, Y. A context-aware mobile learning system for supporting cognitive apprenticeships in nursing skills training. Educational Technology \& Society, 15(1), 223-236, 2012. 
[25] Hung, J. \& Zhang, K. Examining mobile learning trends 2003 - 2008: A categorical metatrend analysis using text mining techniques. Journal of Computing in Higher Education, 24(1), 1-17, 2012. https://doi.org/10.1007/s12528-011-9044-9

[26] Wu, W., Wu Y.J., Chen, C., Kao, H., Lin, C., \& Huang, S. Review of trends from mobile learning studies: A meta-analysis. Computers \& Education, 59(2), 817-827, 2012. https://doi.org/10.1016/j.compedu.2012.03.016

[27] Chee, K.N., Yahaya, N., Ibrahim, N.H., \& Hasan, M.N. Review of the mobile learning trends 2010-2015: A meta-analysis. Educational Technology \& Society, 20(2), 113-126, 2017.

[28] Mouza, C. \& Barrett-Greenly, T. Bridging the gap app: An examination of a professional development initiative on mobile learning in urban schools. Computers \& Education, 88, 1-14, 2015. https://doi.org/10.1016/j.compedu.2015.04.009

[29] Elfeky, A.I.M \& Masadeh, T.S.Y. The effect of mobile learning on students' achievement and conversational skills. International Journal of Higher, 5(3), 20-31, 2016. https://doi. org/10.5430/ijhe.v5n3p20

[30] Vázquez-cano, E. Mobile distance learning with smartphones and apps in higher education. Educational Sciences: Theory and Practice, 14(4), 1505-1520, 2014. https://doi.org/10.12738/estp.2014.4.2012

[31] Dos, B. The relationship between mobile phone use, metacognitive awareness and academic achievement. European Journal Of Educational Research, 3(4), 192-200, 2014. https://doi.org/10.12973/eu-jer.3.4.192

[32] Hanif, M. \& Asrowi, A. Mobile learning graduate student perception of teachers: A case study in the master program of Educational Technology of the University of the March. International Journal of Multicultural and Multireligious Understanding, 5(1), 84-91, 2018. https://doi.org/10.18415/ijmmu.v5i1.316

[33] Yusri, I.K., Goodwin, R., \& Mooney, C. Teachers and mobile learning perception: Towards a conceptual models of mobile learning for training. in Procedia - Social and Behavioral Sciences, 176, 425-430, 2015. https://doi.org/10.1016/j.sbspro.2015.01.492

[34] Hanif, M., Asrowi, \& Sunardi. Students' access to and perception of using mobile technologies in the classroom: The potential and challenges of implementing mobile learning. Journal of Education and Learning (EduLearn), 12(4), 644-650, 2018. https://doi.org/10.11591/edulearn.v12i4.8398

[35] Pedro, L.F.M.G., Barbosa, C.M.M. de O., \& Santos, CM das N. A critical review of mobile learning in formal educational integration contexts. International Journal of Educational Technology in Higher Education, 15(10), 1-15, 2018. https://doi.org/10.1186/ s41239-018-0091-4

[36] Wang, M., Shen, R., Novak, D. \& Pan, X. The impact of mobile learning on students' learning behaviours and performance: Report from a large blended classroom. British Journal of Educational Technology, 40(4), 673-695, 2009. https://doi.org/10.1111/j.1467$\underline{8535.2008 .00846 . x}$

[37] Aberdour, M. Moodle for mobile learning. UK: Packt Publishing Ltd., 2013.

[38] Marzouki, O.F., Idrissi, M.K., Bennani, S. Effects of social constructivist mobile learning environments on knowledge acquisition: A meta-analysis. International Journal of Interactive Mobile Technologies, 11(1), 18-39, 2017. https://doi.org/10.3991/ijim.v11i1. $\underline{5982}$

[39] Daughtery, C. \& Berge, Z.L. Mobile learning pedagogy. International Journal for the Scholarship of Technology Enhanced Learning, 1(2), 111-118, 2017.

[40] Al Hamdani, D.S. A constructivist approach to a mobile learning environment. International Journal of Computer Applications. 93(4), 41-46, 2014. 
[41] Brown, T.H. \& Mbati, L.S. Mobile learning: Moving past the myths and embracing the opportunities. International Review of Research in Open and Distributed Learning, 16(2), 115-135, 2015. https://doi.org/10.19173/irrodl.v16i2.2071

[42] Narayan, V.L. The mobilised learner: Heutagogy and mobile social media. Thesis (PhD), 2017.

[43] Ben-Eliyahu, A., \& Linnenbrink-Garcia, L., Extending self-regulated learning to include self-regulated emotion strategies. Motivation and Emotion, 4(5), 1-8, 2008. https://doi.org/ $10.1007 / \mathrm{s} 11031-012-9332-3$

\section{Authors}

Ika Lestari is a lecturer from the Elementary School Teacher Education study program, Faculty of Education, Jakarta State University, Indonesia. She also became an evaluator for opening study programs at the Ministry of Research, Technology and Higher Education.

Arifin Maksum is a lecturer from the Elementary School Teacher Education study program, Faculty of Education, Jakarta State University, Indonesia. He is also an assessor at the National Accreditation Agency for the Elementary School Teacher Education Study Program.

Cecep Kustandi is a lecturer from the Educational Technology study program, Faculty of Education, Jakarta State University, Indonesia. Actively, writing some books about Instructional Media, pursuing technology-based media, and helping several ministries and institutions develop e-learning and multimedia.

Article submitted 2019-06-03. Resubmitted 2019-07-20. Final acceptance 2019-07-20. Final version published as submitted by the authors. 